\title{
A clinical perspective on electronically collecting patient-reported outcomes at the point-of-care for overactive bladder
}

\author{
Darren Desantis, MD; ${ }_{1}^{1}$ Richard J. Baverstock, MD ${ }^{-1,2}$ Andrea Civitarese, BSc; ${ }_{1}^{1}$. Trafford Crump, PhD; ${ }^{2}$ \\ Kevin V. Carlson, $M D^{1,2}$
}

'vesia [Alberta Bladder Centre]; 2University of Calgary, Department of Surgery, Calgary, AB, Canada

Cite as: Can Urol Assoc J 2016;10(11-12):E359-66. http://dx.doi.org/10.5489/cuaj.3757 Published online November 10, 2016.

\section{Abstract}

Introduction: Collecting patient-reported outcomes (PROs) can inform the treatment and management of overactive bladder (OAB). However, collecting these data at the point-of-care can be timeconsuming and have a negative impact on a clinic's workflow. The purpose of this study was to pilot a digital system for collecting PROs at the point-of-care and qualitatively assess clinicians' perspectives in terms of the system's impact on the delivery of care for OAB.

Methods: Patients visiting a urology clinic for OAB completed several PRO instruments using a tablet while awaiting assessment. Clinicians reviewed their responses using a digital dashboard during clinical encounters. Qualitative interviews were conducted with the clinicians, to assess the collection system's impact in terms of: 1) logistics, 2) workflow; 3) patient communication; 4) influence on clinical decisions; 5) user experiences; and 6) the care model. Results: Six interviews were conducted and thematic saturation was met, with several themes emerging. All participants were generally positive regarding the use of the digital collecting system. Participants felt that the dashboard improved workflow and enhanced communication with patients, but it was not thought to be any more influential on clinical decision-making than conventional collection methods. Several aspects of the digital PRO collection system were identified as needing improvement.

Conclusions: The digital PRO collection system used at the pointof-care had a positive impact on the delivery of care for OAB. The results from this study could provide insight to other urologists who are interested in collecting PROs in their clinic.

\section{Introduction}

Treating overactive bladder $(\mathrm{OAB})$ can be challenging, in part because clinical endpoints are not well-defined. ${ }^{1}$ Additionally, objective assessment tools used to measure biologic responses to interventions do not inform clinicians as to whether those interventions made a noticeable differ- ence to the patient. ${ }^{2}$ Like many chronic conditions, interventions for $\mathrm{OAB}$ are aimed more at minimizing symptoms to a level tolerable to the patient. Symptom severity will differ by patient, as will the impact those symptoms have on a patients' quality of life. ${ }^{3}$ If this impact can be assessed, clinicians can meaningfully adjust their management of the patient's OAB.

One way to assess and quantify the severity of symptoms related to $O A B$ is through the use of patient-reported outcomes (PROs). Originally designed for use in randomized control trials, PROs directly assess a patient's health, functional impairments and disabilities, and severity of symptoms using standardized survey instruments. Advancements in PRO instrument development and technology are driving more clinicians to use PROs as part of a comprehensive approach to the delivery of care. ${ }^{4}$ Specific to the treatment of $\mathrm{OAB}$, the Fourth International Consultation on Incontinence recommendations regarding effective care of lower urinary tract symptoms (LUTS) includes assessing patient symptoms and health-related quality of life. ${ }^{5}$

However, collecting PROs at the point-of-care can be difficult and time-consuming. ${ }^{6}$ First, patients may not have access to the same level of support when completing PROs as they do when completing PROs as part of clinical trials, resulting in less complete information. Second, the data collected using the PRO instrument must be scored and interpreted prior to the patient-clinician encounter.

To address these challenges, our clinic set out to test the collection of PROs electronically, using a tablet in the patient waiting room. This approach holds several advantages over the conventional paper-and-pencil mode of administration. The purpose of this case study was to pilot such a system and qualitatively assess the clinicians' perspectives in terms of the system's impact on the delivery of care for OAB. 
Desantis et al.

\section{Methods}

\section{Development of the electronic PRO collection system}

The digital PRO collection system (digiPRO) was developed for the purpose of this study. The system was comprised of two inter-related parts. The first part was the data capturing application, which included three PRO instruments: Overactive Bladder-8 (OAB-V8), ${ }^{7}$ the International Prostate Symptom Score (IPSS), ${ }^{8}$ and the Patient Perception of Bladder Condition (PPBC). ${ }^{9}$ These instruments were selected because the paper-and-pencil formats were already being used in the clinic. The application was designed for touch input using a tablet device, with responses to each question appearing in a dropdown menu. An example of the input screen is included in Fig. 1.

The second part of the digiPRO was the dashboard. For each of the three PRO instruments, the system would analyse the newly entered PRO data, link it to any previous PRO data for that patient (the system was loaded with patients'

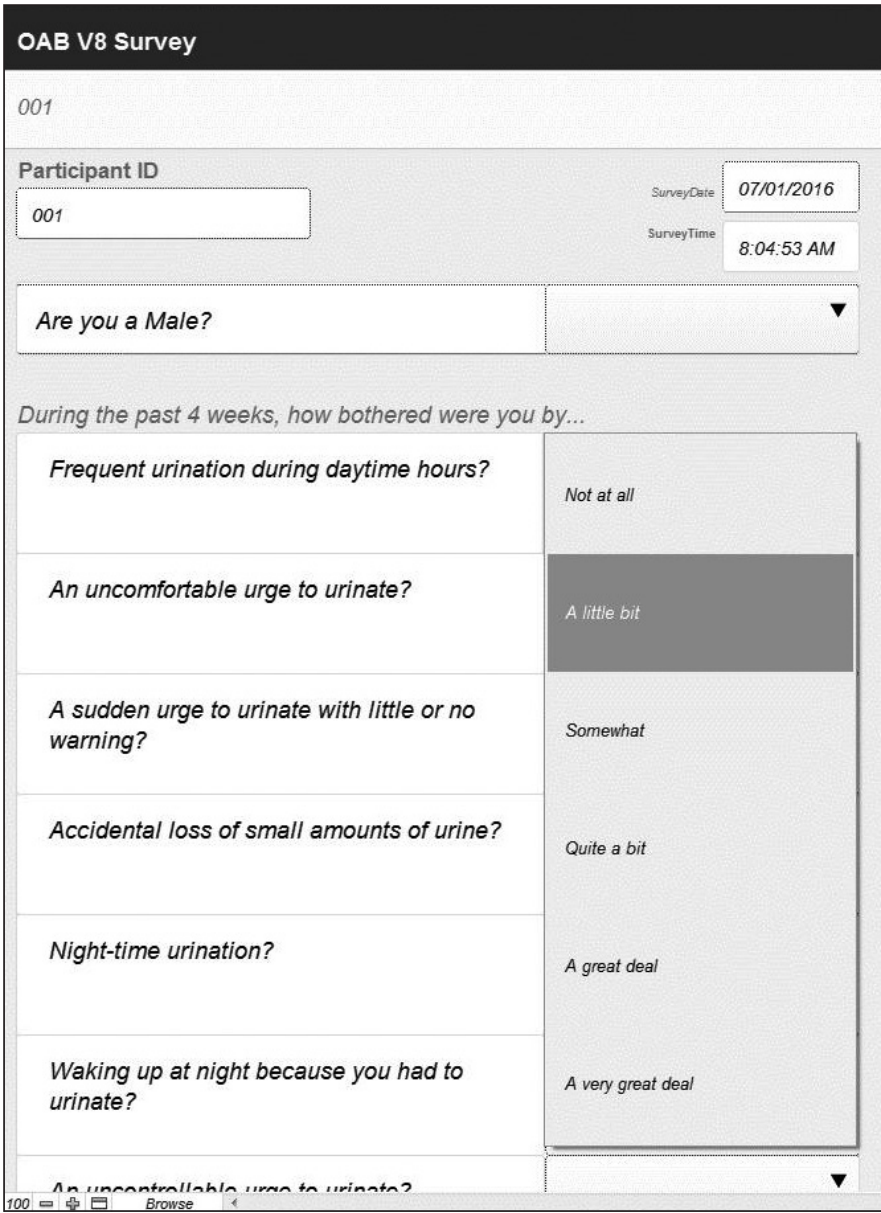

Fig. 1. Example of the patient-reported outcome data entry screen, as seen by patients. previous PRO data collected from the paper instruments), and produce a longitudinal line graph of the scores. The resulting three graphs (one for each PRO instrument) were displayed as a dashboard, which could be viewed on a tablet or computer. Fig. 2 provides an illustrated example of this dashboard. The system was developed using FileMaker version 13 and the FileMaker Go app for iOS (FileMaker Inc.; Santa Clara, CA, U.S.).

\section{Clinical setting}

The study was conducted at vesia [Alberta Bladder Centre], located in Calgary, $\mathrm{AB}$, Canada. This multidisciplinary clinic is presently comprised of two urologists, two urology fellows, one gynecologist, an internal medicine physician, three general practitioners, and a team of nurses and physiotherapists. Vesia is the primary referral centre for LUTS in the Calgary Zone of Alberta Health Services, which has a population of approximately 1.6 million. The clinic has an average annual volume of 18000 visits from approximately 8700 unique patients.

\section{Intervention}

Patients being treated for $\mathrm{OAB}$ at vesia between August 1 and October 31, 2015 were asked to complete their PRO surveys using the digiPRO at the time of checking in for their appointment. Front office staff provided patients with a tablet device with the application and connected to the clinic's wireless network. They were asked to complete the PRO surveys while they were seated in the waiting area. The front office staff was available to assist patients with any questions or concerns. Upon completing the surveys, the patients returned the tablet device to the front office staff. Vesia's clinicians were asked to view the dashboard in the assessment room during the clinical encounter with the patient. They could view the dashboard on either the assessment room computers or on a tablet device of their own.

\section{Study design}

Semi-structured interviews were completed with a sample of vesia's clinicians. To guide these interviews, a conceptual framework was developed based primarily on two sources: part 1) care recommendations for LUTS, as laid out by the Fourth International Consultation on Incontinence; ${ }^{8}$ and part 2) documented considerations to using PROs in surgical care and performance measurement. ${ }^{10}$ This framework is illustrated in Fig. 3.

All of vesia's clinicians were solicited to participate in the study. These clinicians had varying levels of experience using PROs collected by the conventional paper-and-pencil methods in their clinic. A research assistant (A.C.) conduct- 


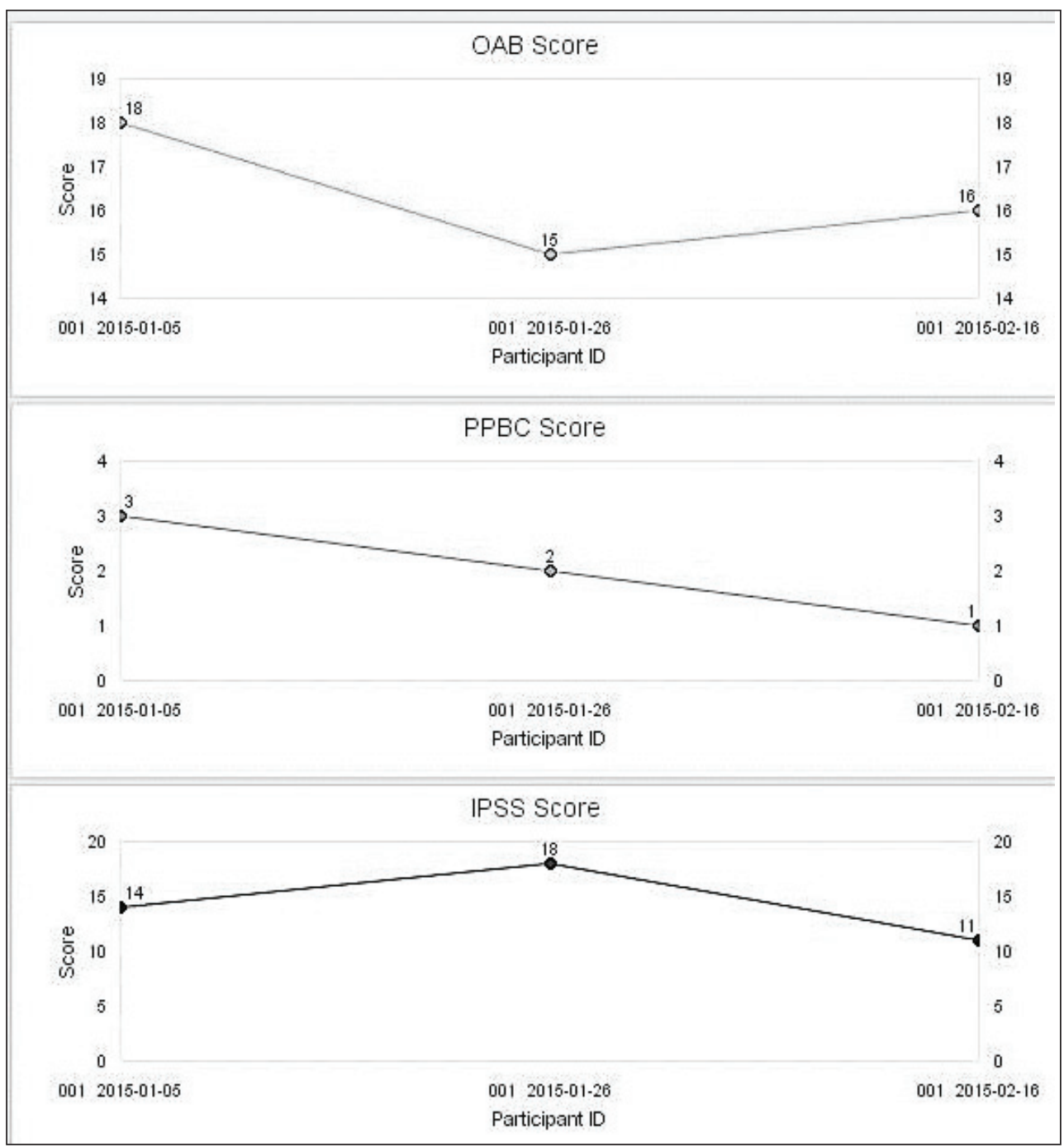

Fig. 2. Example of the patient-reported outcome dashboard, as seen by the clinician.

ed the interviews at the clinic either before or after clinic. The interview script included initial questions, with possible probes and followup questions based on participants' responses. The script was developed by the research team who were not involved in the use of the dashboard.

Each interview was digitally audio-recorded and manually transcribed. Field notes were kept during the interview, but were not deemed to provide any additional information beyond that captured in the recording. The transcriptions were not returned to participants for review or comment.

Given the rather narrow research question at the centre of this study, we took what Green et al refer to as a pragmatic approach to our sample strategy. ${ }^{11}$ This approach is appropriate for eliciting thoughts regarding the main theme of interest, rather than developing new theory. Guest et al stated that such work can be achieved in sample sizes between six and $12 .{ }^{12}$

\section{Analysis}

Analysis was conducted using the Framework approach. ${ }^{13}$ Transcriptions of the audio-recordings were analyzed for themes. Both the transcription and analysis were completed using NVivo for Mac version 10.2.1 (QSR International (Americas) Inc.; Burlington, MA, U.S.). The transcriptions were coded into themes based on the conceptual framework: logistical issues, workflow issues, impacts on patient communication, influence on clinical decisions, user experiences, and changes to the care model. Items that did not fall within a predefined theme in the conceptual model were coded as "other concerns." A single data coder was responsible for coding all transcriptions. Participants were provided with the results and asked for their feedback.

Clinicians were required to provide signed informed consent before participating in this study. This study was approved by the University of Calgary's Conjoint Health 


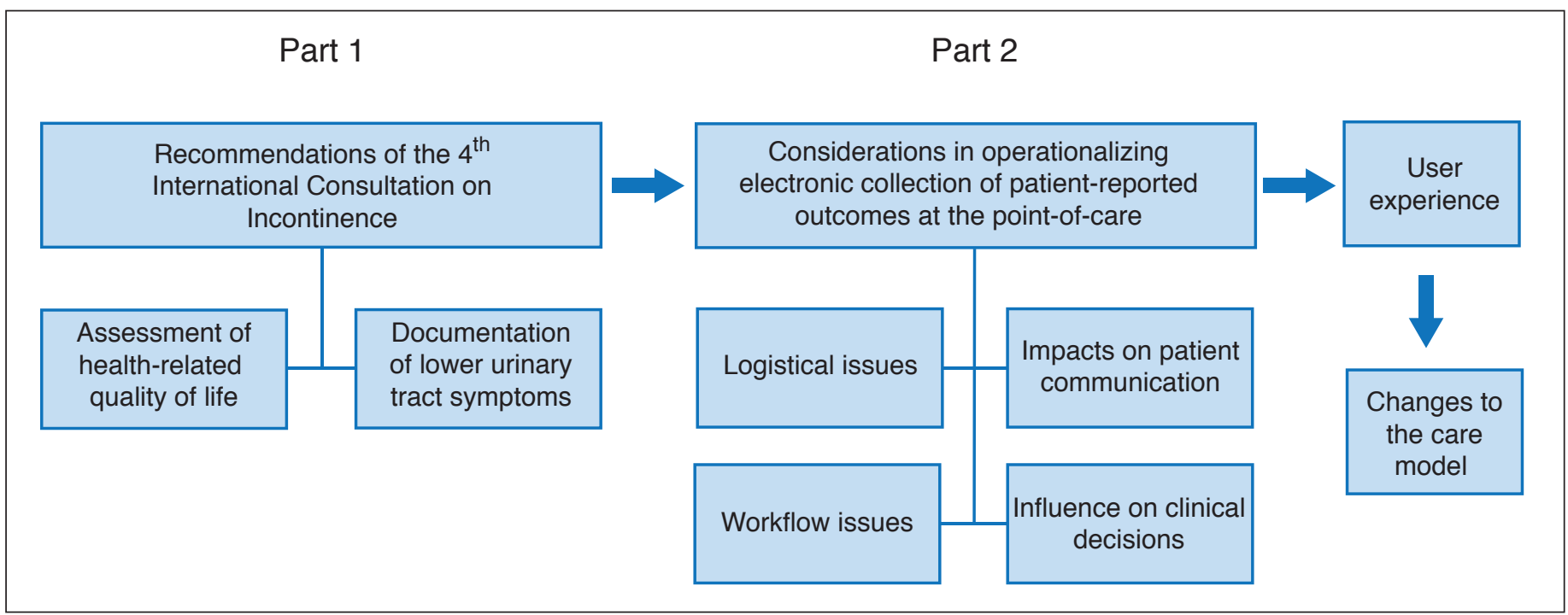

Fig. 3. Conceptual framework.

Research Ethics Board. Reporting of this study is based on the consolidated criteria for reporting qualitative studies (COREQ). ${ }^{14}$

\section{Results}

Six of eight clinicians were interviewed (response rate $75 \%$ ); all were male. Five were urologists and one was a general practitioner. The mean time of semi-structured interview was 7:26 minutes (standard deviation 0.10, range 3:54-9:56 minutes). Thematic saturation was met with these six interviews. Using line-by-line coding, qualitative analysis resulted in designation of items within the six themes identified in the conceptual model; however, some items required subclassification within a theme. A table of the themes and subthemes, along with illustrative quotes, are provided in Appendix A.

\section{Logistics}

Specifically, within the logistics theme, participants identified several areas of improvement in the overall operation of the dashboard. Two minor suggestions were to improve the method of logging into the dashboard and to add functionality to allow printing of results. Suggested major changes included the incorporation of the dashboard login into the electronic medical records (EMRs) and making changes to the data display that included: adding dates of treatment change, allowing display of scores by individual questions or symptoms, providing a more dynamic display of previous questionnaire scores, and the integration of notifications within the display.

\section{Workflow}

A major consideration in this study was the impact of the dashboard on clinician workflow. Overall, participants felt that the dashboard improved workflow, as it reduced the need to open multiple previous questionnaires to compare a patient's results over time. They did identify some changes that would improve these workflow considerations, including integration with their EMRs to minimize interface requirements during the patient encounter; and increased granularity of the data to include individual question scores in addition to global scores, allowing the monitoring of specific symptoms.

\section{Patient communication}

Participants reported that the dashboard would enhance communication with patients because the graphical display could be used to explain changes in symptoms over time. They also felt that it had the potential to enhance the ability to communicate changes in the patient's condition with the referring physician.

\section{Influence on clinical decisions}

Participants provided many comments on how the dashboard impacted clinical decisions. One subtheme that emerged was interest in creating a flagging system within the dashboard that could be used to identify large changes in symptoms. Flags, for example, could be tied to minimally clinical important differences where these are published. The overall sense was that such a flagging system would be beneficial provided it was not overly sensitive. 
Participants mentioned that some of the impact on clinical decision-making may not differ between the paper and dashboard versions of PROs. However, they did comment that the graphical display of the results over time could enhance the ways in which they approach patient assessment, prepare for patient encounters, and most notably, make adjustments to the patient's care plan based on changes in their symptoms.

\section{User experience and changes to care model}

All participants were generally positive regarding the use of the dashboard, and were enthusiastic about moving forward with it, rather than traditional paper-and-pencil methods. They also provided feedback that increasing the collection of PROs data could offer several benefits, including: understanding the impact that treatment changes have on symptom scores; identifying potential worsening of symptoms and addressing them if needed prior to the next followup appointment; and having additional information on a patient's symptoms when preparing for the next followup appointment. Participants were uniform in stating that increasing the frequency of PRO collection would be beneficial, but not more than monthly over concerns for both patient and clinician fatigue in reviewing results.

\section{Discussion}

This study demonstrates the feasibility of collecting PROs electronically in a busy multidisciplinary bladder clinic with high volumes of ambulatory care patients. In general, the clinicians who participated in the qualitative interviews found the dashboard to be a useful tool that not only improved the process of collecting PROs from patients, but also improved the way the PRO data informs clinical decisions and the delivery of care. This electronic collection model could be used to replace the conventional paper-and-pencil model.

The clinicians who participated in this study did identify several improvements that could be made to the dashboard, including simplifying the login screen; adding more detail to the display of the graphical results over time; and incorporating the ability to print the screen or save as a portable document file (pdf) to share with the referring physician. These suggestions would be useful improvements and would be fairly easy to incorporate into a second version of the digiPRO.

Workflow considerations were a concern for the researchers before implementing the electronic PROs and dashboard system. In general, the participants felt that the dashboard did not hinder workflow and several mentioned that it improved it, in particular allowing the clinician to look at a patient's results over time on one graph rather than pulling out multiple paper copies of previous questionnaires.
Workflow concerns would be further improved if the login process were faster and better integrated with other patient care or documentation tools.

Much feedback was provided by the participants about the potential impacts of the digiPRO on improving communication with the patient. This is consistent with observations from other studies involving PROs. ${ }^{7,15,16}$ Participants also thought there to be several advantages to the digiPRO in assessing patients, adjusting a care plan, and preparing for patient care. Again, similar observations have been noted in other studies. ${ }^{17,18}$

\section{Limitations}

This qualitative study was limited to a small sample of clinicians practicing at one community-based urological clinic in Calgary, Canada. The results may not be generalizable to other non-urological clinics or those in other settings. Additionally, the clinicians were familiar with the use of PROs in paper form so fundamental concerns of incorporating PROs into a clinical setting were not raised. Clinicians who are incorporating PROs for the first time (whether paper or electronic) may identify different concerns than the participants in our interviews.

\section{Future research}

Patient perspectives of using the digiPRO were not gathered for this study. While participants did not mention any patient complaints in completing their questionnaires on a tablet rather than paper, one participant noted a concern about patient comfort in using a tablet or other electronic method to collect the PRO information. While previous research suggests that patient compliance in PRO questionnaires does not drop with the use of electronic data collection, ${ }^{19}$ a future research study or internal evaluation should be undertaken with our patients to determine if there are concerns or barriers to PRO completion using electronic vs. paper collection. Patients should also be asked for their opinions on how the dashboard impacts communication with their clinician, along with their overall care.

\section{Conclusion}

In general, the digital PRO collection system used at the point-of-care had a positive impact on the delivery of care for $O A B$. The system improved workflow and enhanced communication with patients, without any consequences on the clinical workflow. Several areas in need of improvement were identified, both in terms of the collection of PROs and their use in the clinical setting. The results from this study could provide insight to other urologists who are interested in collecting PROs in their clinic. 
Desantis et al.

Competing interests: Dr. Baverstock has been an advisor for Allergan, Astellas, and Pfizer; a speaker for Allergan, AMS, Astellas, and Pfizer; has received honoraria from Allergan, AMS, Astellas, and Pfizer; and has participated in clinical studies for Allergan, Astellas, and Pfizer. Dr. Carlson has been an advisor for and received honoraria from Astellas, Ferring, and Pfizer; and has participated in clinical trials for Astellas, Aquinox, and Cook MyoSite.The remaining authors report no competing personal or financial interests.

This paper has been peer-reviewed.

\section{References}

1. Payne CK and Kelleher C. Redefining response in overactive bladder syndrome. BJU Int 2007:99:101-6. http://dx.doi.org/10.1111/i.1464-410X.2007.06517.x

2. Fairclough DL. Patient-reported outcomes as endpoints in medical research. Stat Methods Med Res 2004;13:115-38. http://dx.doi.org/10.1191/0962280204sm357ra

3. Brubaker L, Chapple C, Coyne KS, et al. Patient-reported outcomes in overactive bladder: Importance for determining clinical effectiveness of treatment. Urology 2006;68:3-8. http://dx.doi.org/10.1016/i. urology.2006.05.045

4. Jensen RE, Rothrock NE, Dewitt EM, et al. The role of technical advances in the adoption and integration of patient-reported outcomes in clinical care. Med Care 2015;53:153-9. http://dx.doi.org/10.1097/ MLR.0000000000000289

5. Abrams $P$, Andersson KE, Birder L, et al. Fourth International Consultation on Incontinence Recommendations of the International Scientific Committee: Evaluation and treatment of urinary incontinence, pelvic organ prolapse, and fecal incontinence. Neurourol Urodyn 2010;29:213-40. http://dx.doi.org/10.1002/ nau.20870

6. Rose M, Bezjak A. Logistics of collecting patient-reported outcomes (PROs) in clinical practice: An overview and practical examples. Qual Life Res 2009;18:125-36. http://dx.doi.org/10.1007/s11136-0089436-0

7. Coyne KS, Zyczynski T, Margolis MK, et al. Validation of an overactive bladder awareness tool for use in primary care settings. Adv Ther 2005;22:381-94. http://dx.doi.org/10.1007/BF02850085
8. Barry MJ, Fowler FJ Jr, O'Leary MP, et al; The American Urological Association symptom index for benign prostatic hyperplasia. The Measurement Committee of the American Urological Association. J Urol 1992;148:1549-57; discussion 1564.

9. Coyne KS, Matza LS, Kopp Z, et al. The validation of the patient perception of bladder condition (PPBC): A single-item global measure for patients with overactive bladder. Eur Urol 2006;49:1079-86. hitp:// dx.doi.org/10.1016/i.eururo.2006.01.007

10. Greenhalgh J. The applications of PROs in clinical practice: What are they, do they work, and why? Qual Life Res 2009;18:115-23. htrp://dx.doi.org/10.1007/s11136-008-9430-6

11. Green J, Thorogood N. Qualitative Methods for Health Research. Introducing qualitative methods. Third Edition. SAGE Publishing, 2014.

12. Guest, $G$, Bunce, A, Johnson, L. How many interviews are enough? An experiment with data saturation and variability. Field Methods 2006;18:59-82. http://dx.doi.org/10.1177/1525822X05279903

13. Ritchie J, Lewis J, Nicholls CM, et al. The foundation of qualitative research. Qual Res Pract A Guid Soc Sci Students Res 2013:0-25.

14. Tong A, Sainsbury P and Craig J. Consolidated criteria for reporting qualitative research (COREQ): A 32-item checklist for interviews and focus groups. Int I Qual Heal Care 2007;19:349-57. http://dx.doi. org/10.1093/intahc/mzm042

15. Valderas $J M$, Kotzeva A, Espallargues $M$, et al. The impact of measuring patient-reported outcomes in clinical practice: A systematic review of the literature. Qual Life Res 2008;17:179-93. http://dx.doi. org/10.1007/s11136-007-9295-0

16. Velikova $G$, Booth $L$, Smith $A B$, et al. Measuring quality of life in routine oncology practice improves communication and patient well-being: A randomized controlled trial. J Clin Oncol 2004;22:714-24. http://dx.doi.org/10.1200/JC0.2004.06.078

17. Jones IB, Snyder CF, Wu AW. Issues in the design of internet-based systems for collecting patient-reported outcomes. Qual life Res 2007;16:1407-17. http://dx.doi.org/10.1007/s11136-007-9235-z

18. Snyder CF, Blackford AL, Wolff AC, et al. Feasibility and value of patient viewpoint: A web system for patient-reported outcomes assessment in clinical practice. Psychooncology 2013;22:895-901. http:// dx.doi.org/10.1002/pon.3087

19. Gwaltney CJ, Shields AL, Shiffman S. Equivalence of electronic and paper-and-pencil administration of patient-reported outcome measures: A meta-analytic review. Value Heal 2008; 11:322-33. http://dx.doi. org/10.1111/j.1524-4733.2007.00231

Correspondence: Dr. Trafford Crump, University of Calgary, Calgary, AB, Canada; tcrump@ucalgary.ca 


\section{Appendix A. Themes and illustrative quotes}

\section{Theme}

Illustrative quote

\section{Logistics}

"It would be nice if you just put in the patient's number and hit enter and it came up, but other than that it was fine." (Participant ID \#4)

"The interface would be better if it was linked into the EMR (electronic medical record), so using a third-party program was a bit of a barrier to have to do a second login." (Participant ID \#3)

Logging in/

system/layout

"Probably the only thing was...remembering to not hit the enter [button] or where [the dashboard] was, you know, on the layout. You have to pick...it doesn't come right to the dashboard layout." (Participant ID \#5)

"I think the ability to print screen, or import graph, so that somehow you could take this data and put it straight into your patient record and most importantly, put it into the letter back to the GP would be pretty useful for us." (Participant ID \#6)

"We need some way to say you're in your target range, or you've reached an impressive improvement. Or even, with the OAB-V8, if all the scores are coming from nocturia, ideally, it would warn the doctor: "Make sure you are addressing nocturia," and then here are the suggestions [for treatment]." (6)

"...it would be an amazing upgrade...to be able to hover over a data point and have the whole thing kind of show in front of you. Because sometimes with some of the questionnaires you like to see exactly what component remains bothersome or is it at the beginning or what component got better more than others...so I guess it could be a little more granular in that sense." (3)

Changes to "It would be nice if as I'm going through, say I'm looking back, if I could double click on the date of that score and it data display would link me to that questionnaire. When I see an OAB-V8 score of 8, I often want to know what part of [the symptoms in the OAB-V8] are bothersome, is it the urgency, the nocturia, the incontinence? And so if I am looking back and see this patient two years ago had a score of 17 ...I'd like to be able to click on that data point and open up that questionnaire." (2)

"If there was any way of saying, this is what we changed at this point...then I would find that to be quite helpful because it would show us what [treatment] either made the improvement or made things worse." (1)

"A lot of our patients are elderly, would be intimidated by the technology to start with, if they've never handled an iPad. It might just throw patients off to start with, and I wonder if that might potentially be a confounder for skewing results,

Technology but I think early on if the office staff was willing to help patients through it that would possible, but they are super busy as it is, so I think it could be a potential barrier for patients." (2)

Workflow

“Well the PROs [electronic] are nice because the graph makes it look so much easier...but it does use a total score as opposed to when you look at the PROs and you break it down into each question, you can really compare question for question when you have the paper form, and with the graphs you're really getting an overall impression of how they're doing...like it's really good for bother scores and its really good for overall sum of how the patient is doing, but I still use Workflow the paper for individual questions as well." (6)

"I think it kind of just creates a picture as to someone's overall trend, so just makes a visual image that you can see where they are with their treatment and that they are on the right course." (4)

"If we are able to work it into an EMR so that you could have it as part of their patient record that would be ideal." (1)

\section{Patient communication}

"...it would be nice to bring it up on the screen and show them during the visit. A graphical representation is a lot easier than using numbers for them when they don't really have a frame of reference for the numbers themselves." (2)

"I think the conversation's gonna just be the same, it's just being able to present the data to the patient in a way that is easily comprehensible." (4)

"I think if it was for the patient, if you broke it down into mild, moderate, and severe in terms of what does this mean, if you say your symptoms are in the mild because you're in the green or your symptoms have moved into the yellow

Patient communication moderate and the red...you could show them, hey, you were red and now you moved into the green and that might be a good visualization." (6)

“Often [the patients] say 'I'm not that much better', then you ask them a question and [the result] is quite a bit different so if they would be able to see [on the dashboard], this is what you said last time...they could see, 'oh maybe it is [different]'." (5)

“I show them the graphs, I find the visual graph...here's where you were, here's where you are now, we really haven't made much difference or we're making improvement...then ask them, 'Does that seem to fit with how you are doing?' [and they may say,] 'Oh no, doctor, I'm doing way better than that'." (6) 
Desantis et al.

\begin{tabular}{|c|c|}
\hline \multicolumn{2}{|c|}{ Appendix A (cont'd). Themes and illustrative quotes } \\
\hline Theme & Illustrative quote \\
\hline \multicolumn{2}{|c|}{ Influence on clinical decisions } \\
\hline \multirow{3}{*}{$\begin{array}{l}\text { Flagging } \\
\text { system }\end{array}$} & $\begin{array}{l}\text { "It would have to be some threshold for when the red flag would be raised, but yeah, it probably wouldn't hurt. } \\
\text { Hematuria, would be one...I don't know if that is on the scoring system now...that would be the biggest one." (1) }\end{array}$ \\
\hline & "I think it may be cumbersome for every question." (2) \\
\hline & $\begin{array}{l}\text { "There are a lot of flags that come through [the EMR] now, and it is kind of hard to respond to, but if something is critical } \\
\text { it is nice to kind of always have the flags so we can get to it when we can instead of discovering it weeks later when the } \\
\text { patient finally shows up in clinic." (4) }\end{array}$ \\
\hline $\begin{array}{l}\text { Changes } \\
\text { to patient } \\
\text { assessment }\end{array}$ & $\begin{array}{l}\text { "I used questionnaires to really confirm that my treatment is working as I interpret it because I don't find that patients } \\
\text { ever had a sense of what their questions were before...so I've always found questionnaires are really for me to say, but } \\
\text { you are doing well, or you aren't doing well, but the problem is it still comes down to number } 1 \text { with the patient: 'How } \\
\text { are you doing with this treatment?' and then they'll have their own assessment. It is just one more thing to help assess } \\
\text { how the patient is doing." (6) }\end{array}$ \\
\hline \multirow{3}{*}{$\begin{array}{l}\text { Changes to } \\
\text { care plan }\end{array}$} & $\begin{array}{l}\text { "I think if you see the patient is not doing well you really adjust your care, so if you see them come down and then go } \\
\text { back up since your last intervention, that's where you'd say, 'What the heck am I doing?" }\end{array}$ \\
\hline & $\begin{array}{l}\text { "...you really respond in medicine to spikes and troughs, and so you get the spikes and troughs with that, much like } \\
\text { following a PSA or following a creatinine, so you see that visual spike and then you're like, 'What do I need to do to make } \\
\text { that turn around and come down?" (6) }\end{array}$ \\
\hline & $\begin{array}{l}\text { "If I saw that the responses to the questionnaires were higher than before...if the trend is in the wrong direction then I } \\
\text { think that I would definitely change my conversation with the patient, I would change their treatment strategy as well." } \\
\text { (4) }\end{array}$ \\
\hline \multirow{2}{*}{$\begin{array}{l}\text { Preparing for } \\
\text { patient care }\end{array}$} & $\begin{array}{l}\text { "I don't know what everyone else does, but I usually review and plan kind of the people I'm seeing because I'm only here } \\
\text { a day a week, but it helps me going in because I can't remember from three months ago who they were and how they } \\
\text { were doing." (5) }\end{array}$ \\
\hline & $\begin{array}{l}\text { "Having that graphical representation provides me reference going back further that I may otherwise review on every } \\
\text { visit, so it could change in some patients, but I have access to the information, it's just more easily available [on the } \\
\text { dashboard]." (2) }\end{array}$ \\
\hline \multirow{4}{*}{$\begin{array}{l}\text { User } \\
\text { experience }\end{array}$} & "I want [the dashboard] live, I want to use it all the time." (6) \\
\hline & $\begin{array}{l}\text { "Overall very easy to use. It was pretty easy and pretty straightforward. I really like how everything was graphical and } \\
\text { pretty easy to visualize what direction the patients were heading." (1) }\end{array}$ \\
\hline & "I think it is very easy to use, it's laid-out well, and easy to figure out." (2) \\
\hline & “My experience is very positive." (3) \\
\hline \multirow[t]{2}{*}{$\begin{array}{l}\text { Changes to } \\
\text { care model }\end{array}$} & $\begin{array}{l}\text { "I don't know that anything more often than maybe monthly would be useful. Some of these symptoms change based } \\
\text { on day-to-day lifestyle choices, so I don't know that that information would be as useful, but potentially monthly because } \\
\text { a lot of these patients will stop medications at home on their own and so if I am treating someone for OAB and I tell } \\
\text { them, 'You can stop this medication if you have these side effects,' if I know the date they stopped them and I can follow } \\
\text { the change in their scores at home, real-time, based on this that they are filling out at home, that would be useful. And so } \\
\text { maybe instructing patients, 'If you stop this medication or if you up-titrate the dose of X medication, let us know when or } \\
\text { record on the dashboard when you changed that medication," we can say to them, 'Look, your scores are worse when } \\
\text { you stopped the medication or better when you up-titrated the med."” (2) }\end{array}$ \\
\hline & $\begin{array}{l}\text { "I often will start somebody on a new medicine and because I know I'm not going to see them for three months, I will } \\
\text { say that at the end of the } 28 \text {-day sample, 'Complete these PROs and send them into me'; when they send them back into } \\
\text { to me, it is a trigger to review their case and see how are they doing, did my intervention work, so I think monthly would } \\
\text { be very useful." (6) }\end{array}$ \\
\hline
\end{tabular}

